\title{
A STUDY OF MORBIDITY PROFILE OF GERIATRIC POPULATION IN THE FIELD PRACTICE AREA OF RURAL HEALTH TRAINING CENTRE, PAITHAN OF GOVT. MEDICAL COLLEGE, AURANGABAD
}

\author{
Jadhav V.S*, Mundada V.D*, Gaikwad A.V**, Doibale M.K**, Kulkani A.P*** \\ * Lecturer, **Associate Professor, *** Prof. \& Head of Dept. \\ Dept. of Preventive and Social Medicine, Govt. Medical College, Aurangabad (M.S)
}

\begin{abstract}
1. Research Question: What is the morbidity profile pattern of geriatric population in rural area?

2. Objectives : i) To study the morbidity profile of elderly

ii) To study the addiction problems among elderly.

3. Study design: Cross - Sectional Study

4. Settings: Field practice area of R.H.T.C, Paithan of Govt. Medical College, Aurangabad.

5. Participants: Elderly above 60 years of age.

6. Sample size: 625 which was $20 \%$ of total elderly at RHTC, Paithan.

7. Statistical analysis: Chi- Square

8. Results: We concluded that the prevalence of Cataract was $40.16 \%$,joint pain-23.04\%,

C.O.P.D-7.52\%, Senescent forgetfulness- $10.88 \%$, hemorrhoids $-8.64 \%$, BEP- $7.20 \%$ in elderly males, hearing impairment $-24.8 \%$, hypertension $-21.6 \%$ and diabetes mellitus $-13.92 \%$, anemia $-8.32 \%$ was present in elderly. Prevalence of addiction among males was $68.34 \%$ and among females $45.42 \%$ elderly females use to chew tobacco.
\end{abstract}

\section{INTRODUCTION}

The two extremes of life child and elderly need special care. Elderly life is full of problems - physical, social and economic. While ageing of the population is essentially a simple phenomenon, its consequences are multiple and not always well recognized. It is rightly said by Sir James Sterling Ross- "You do not heal old age, you protect it, you promote it, you extend it". 'The elderly are afflicted by the process of ageing which causes a general decline in health

Certain diseases are more frequent among elderly that the young people, degeneration diseases of heart and blood vessels, cancer, accidents, diabetes, diseases of locomotor system, respiratory illness, genitor-urinary tract diseases.

In India, although the percentage of aged persons to the total population is low in country, nevertheless, the absolute size of the aged population is considerate. Elderly with disability resulting from chronic diseases appear at high risk of acute illness and injuries.

Although Primary Health Centres along with their sub- centres are distributed all over the country. They are not able to avail all the facilities at the PHC or its sub-centres owing to lack of transport, geographical distance, or physical disabilities or for want of funds and physical help for travel.

There is ample scope for research into the degeneration and other diseases of elderly their treatment in hospital and general practice and family into preventive geriatrics and the epidemiology affecting the elderly.

\section{MATERIAL AND METHODS:}

The present study was carried out at the field practice area of Rural Health and Training Center, Paithan of Government Medical College, Aurangabad during the period of $1^{\text {st }}$ Sept- 2006 to $31^{\text {st }}$ August -2007.

Total elderly population according to the above definition at the field practice area of Rural Health and Training Center (RHTC), Paithan was 3128. Enlisting of the study subjects was done by systematic random sampling by using Loksabha electoral list of 2005. A sample of $20 \%$ of total elderly population was taken by including every fifth elderly from the electoral list. 
Home visit was paid to study subjects and were interviewed and examined for health and socio-economic problems.

Elderly who had expired or houses of whom were permanently locked or have transferred their residence or elderly who cannot be contacted after three successive visits to their homes were excluded and next elderly in the list was included.

\section{RESULTS:}

Table No. 1-Medical morbidities among elderly in various systems:

The study subjects were interviewed and examined and the following observations were made. Out of total 625 elderly studied, $328(52.48 \%)$ were females and $297(47.52 \%)$ were elderly males. All the elderly included in the study were thoroughly examined for any systemic disease or physical defects. Present complaints were asked initially and according to it, following the proforma elderly was examined.

General examination by taking pulse rate, blood pressure etc was carried out. Then systemic examination was carried out. The criteria laid down by standard text books of Medicine, Surgery, OBGY, Ophthalmology, ENT and manual for clinical examination was used for diagnosis of medical conditions and also the help of case paper record available with individuals was taken into consideration.

Table no.1 - shows that $124(41.75 \%)$ males and 127(38.71\%) in females had Cataract in single or both eyes. Presbyopic morbidity was present in 26(8.75\%) males and 42(12.80\%) females. $10(3.36 \%)$ males and 3(0.91\%) females had active conjunctivitis. While $7(2.35 \%)$ males and $6(1.82 \%)$ females had pterygium.

$39(13.13 \%)$ males and 54(16.46\%) females had backache. 5(1.68\%) males and $8(0.91 \%)$ females had complaints of spondylitis. 3 males and 12 females had \# femur due to fall. 38 (12.79\%) males and 46(14.02\%) females had complaints of arthritis.

$30(10.10 \%)$ males and were $17(5.18 \%)$ females suffered from C.O.P.D, 8(2.69\%) males and $6(2.24 \%)$ females had bronchiectasis and 2 males and 1 female were on DOTS. 


\begin{tabular}{|c|c|c|c|c|c|c|}
\hline & \multicolumn{2}{|c|}{$\begin{array}{l}\text { Male } \\
(\mathrm{n}=297)\end{array}$} & \multicolumn{2}{|c|}{$\begin{array}{l}\text { Female } \\
(\mathbf{n}=328)\end{array}$} & \multicolumn{2}{|c|}{$\begin{array}{l}\text { Total } \\
(n=625)\end{array}$} \\
\hline & No. & $\%$ & No. & $\%$ & No. & $\%$ \\
\hline Cataract & 124 & 41.75 & 127 & 38.71 & 251 & 40.16 \\
\hline Hearing impairment & 63 & 21.21 & 92 & 28.04 & 155 & 24.8 \\
\hline Hypertension & 43 & 14.47 & 92 & 28.04 & 135 & 21.6 \\
\hline Diabetes & 31 & 10.43 & 56 & 17.07 & 87 & 13.92 \\
\hline Arthritis & 38 & 12.79 & 46 & 14.02 & 84 & 13.44 \\
\hline Refractive error & 28 & 9.42 & 43 & 13.10 & 71 & 11.36 \\
\hline Senescent forgetfulness & 41 & 13.80 & 27 & 8.23 & 68 & 10.88 \\
\hline Depression & 25 & 8.41 & 42 & 12.80 & 67 & 10.72 \\
\hline Hemorrhoids & 33 & 11.11 & 21 & 6.40 & 54 & 8.64 \\
\hline Anemia & 14 & 4.71 & 38 & 11.58 & 52 & 8.32 \\
\hline$\overline{\text { APD }}$ & 20 & 6.73 & 28 & 8.53 & 48 & 7.68 \\
\hline C.O.P.D & 30 & 10.10 & 17 & 5.18 & 47 & 7.52 \\
\hline Constipation & 28 & 9.42 & 14 & 4.26 & 42 & 6.72 \\
\hline Corneal Opacity & 10 & 3.36 & 22 & 6.70 & 32 & 5.12 \\
\hline Hemiplegia & 18 & 6.06 & 11 & 3.35 & 29 & 4.64 \\
\hline BEP & 22 & 7.40 & -- & -- & 22 & 3.52 \\
\hline Skin disorders & 16 & 5.38 & 06 & 1.82 & 22 & 3.52 \\
\hline Urinary incontinence & 11 & 4.04 & 08 & 2.43 & 19 & 3.04 \\
\hline UTI & 03 & 1.01 & 15 & 4.57 & 18 & 2.88 \\
\hline Fracture femur & 03 & 1.01 & 12 & 3.65 & 15 & 2.40 \\
\hline Bronchiectasis & 08 & 2.69 & 06 & 1.82 & 14 & 2.24 \\
\hline Leprosy & 00 & 00 & 03 & 0.91 & 03 & 0.48 \\
\hline
\end{tabular}


41(13.80\%) males and 27(8.23\%) females were having senescent forgetfulness. While 25(8.41\%) males and $42(12.80 \%)$ had history and symptoms of depression. 18(6.06\%) males and 11(3.35\%) females suffered from Hemiplegia. $3(0.91 \%)$ females were having various deformities of Leprosy.

20(6.73\%) males and 28(8.53\%) females had acid peptic disease, 33(11.11\%) males and 21(6.40\%) females had complaints of hemorrhoids. While 28(9.42\%) males and 14(4.62\%) females had the problem of constipation.

$22(7.40 \%)$ males had complaint and symptoms of benign enlargement of prostate. $15(4.57 \%)$ females were suffering from urinary tract infection. 3(1.01\%) males and 2(0.60\%) females had fecal incontinence while $11(4.04 \%)$ males and $8(2.43 \%)$ females had urinary incontinence. The incidence rates of urge incontinence and stress incontinence were $19.8 \%$ (with $3.1 \%$ often) and $14.5 \%$ (with $1.9 \%$ ), respectively.

$31(10.43 \%)$ males and 56(17.07\%) females were having the complaints of Diabetes mellitus and 43(14.47\%) males and 92(28.04\%) females of hypertension. 38(8.53\%) females were having anemia. 4(1.32\%) males and 10(3.04\%) females were taking treatment for cancer. $16(5.38 \%)$ males and 6(1.82\%) females presented with various skin disorders. While $63(21.21 \%)$ males and $92(28.04 \%)$ females had various degree of hearing impairment.

Table no. 2- Addiction pattern among elderly:

\begin{tabular}{|l|l|l|l|l|l|l|}
\hline Habit & \multicolumn{2}{l}{$\begin{array}{l}\text { Male } \\
(\mathbf{n = 2 9 7})\end{array}$} & \multicolumn{2}{l}{$\begin{array}{l}\text { Female } \\
(\mathbf{n = 3 2 8})\end{array}$} & \multicolumn{2}{l|}{$\begin{array}{l}\text { Total } \\
(\mathbf{n = 6 2 5})\end{array}$} \\
\cline { 2 - 7 } & No. & $\%$ & No. & $\%$ & No. & $\%$ \\
\hline Other & 120 & 40.40 & 166 & 50.60 & 286 & 45.76 \\
\hline Tobacco & 87 & 29.29 & 149 & 45.42 & 236 & 37.76 \\
\hline Smoking & 89 & 29.96 & 00 & 00 & 89 & 14.24 \\
\hline Alcohol & 54 & 18.18 & 00 & 00 & 54 & 8.64 \\
\hline No addiction & 94 & 31.64 & 119 & 36.28 & 213 & 34.08 \\
\hline
\end{tabular}

Table no.2 - shows the addiction habits of elderly. $89(29.96 \%)$ males were smoking and 54(18.18\%) were consuming alcohol. 87(29.29\%) males and 149(45.42\%) females were chewing tobacco. $120(40.40 \%)$ males and 166(50.60\%) females were having addictions like Hukka, Bhang, betel, and pan. While 213(34.08\%) were having no addiction. Significantly higher proportion of males were having addiction of alcohol and smoking $(\mathrm{p}<0.001)$.

\section{DISCUSSION:}

In the present study $122(41.07 \%)$ elderly males were of the 60 - 64 years age group and $88(26.82 \%)$ females were of the 65- 69 years age group.

Present study shows that $124(41.75 \%)$ males and 127(38.71\%) in females had Cataract in single or both eyes. Presbyopia in $26(8.75 \%)$ males and 42(12.80\%) females. $10(3.36 \%)$ males and 3(0.91\%) females had active conjunctivitis. Similarly, Adegbehingbe BO $(2006)^{2}$ found that of the 445 people examined, cataract $30(42.3 \%)$, glaucoma $23(32.4 \%)$ and uncorrected aphakia $7(9.9 \%)$ were the leading causes of blindness and cataract $245(54.2 \%)$ and glaucoma $176(38.9 \%)$ were the most common causes of low vision followed by pterygium $10(2.2 \%)$, corneal opacity $9(1.8 \%)$ and refractive errors 6 (1.3\%). Singh MM (1997) 3 studied the prevalence of low vision was $32 \%$ while that of blindness was $12.2 \%$. There was a high prevalence of refractive errors $(40.8 \%)$, cataract $(40.4 \%)$, aphakia $(11.1 \%)$ followed by pterygium $(5.2 \%)$, glaucoma (3.1\%) and corneal opacities $(3 \%)$. These findings were comparable with present study.

In the present study $39(13.13 \%)$ males and 54(16.46\%) females had backache. 5(1.68\%) males and $8(0.91 \%)$ females complained of spondylitis. 3 males and 12 females had \# femur due to fall. 38 (12.79\%) males and 46(14.02\%) females complained of arthritis.

In a study by Sharma MK (2007) ${ }^{4}$ interviewed and assessed 362 elderly clinically they found that the overall prevalence of osteo-arthritis was 56.6\%; in rural areas it was 32.6\% and in urban, it was $60.3 \%$ (p <0.001). Osteoarthritis was more in females as compared to males $(70.1 \%$ Vs $41.6 \%)$. Anil Jacob Purty (2006) ${ }^{5}$ studied 320 elderly, out of which the elderly most commonly complaint of joint pains/joint stiffness 139(43.4\%). Rahul Prakash $(2004)^{6}$ showed that commonest 
musculoskeletal disease was arthritis $16(8.42 \%)$. These findings are comparable with the present study. 41(13.80\%) males and $27(8.23 \%)$ females were having senescent forgetfulness.

While $25(8.41 \%)$ males and $42(12.80 \%)$ had history and symptoms of depression. 18(6.06\%) males and 11(3.35\%) females suffered from Hemiplegia. 3(0.91\%) females were having various deformities of Leprosy. Which shows that these results are comparable with the present study.

Liu C, Androws GR (2002) ${ }^{7}$ revealed higher prevalence than present study of urge incontinence rate with $36.6 \%$ to $41.6 \%$ of the elderly having atleast an occasional problem (with $7.5 \%$ to $9.6 \%$ having problems often), compared to $23.4 \%$ to $28.8 \%$ having at least an occasional problem with stress incontinence (with $3.3 \%$ to $5 \%$ having problems often.

Similarly in the study carried out by Surekha Kishore $(2007)^{8}$ found that hypertension was the most common problem $(41.4 \%)$, followed by musculoskeletal problems $(36.8 \%)$, respiratory problems $(36.1 \%)$ and psychosocial problems $(28.8 \%)$. Sonia Puri (2007) ${ }^{9}$ found that $40(54.1 \%)$ elderly presented with some sign / symptom for which fasting blood sugar level was done and the patient was found diabetic. $18(24.6 \%)$ were diagnosed on routine investigation and rest $16(21.6 \%)$ accidentally. Anil Jacob Purty (2006) ${ }^{5}$ in his study found hypertension in $83(25.9 \%)$ and diabetes in $26(8.3 \%)$ elderly. Gastrointestinal complaints / diarrhea in $38(12 \%)$, dermatological in $28(9.4 \%)$, and respiratory in $22(7.3 \%)$ were less common. $195(61 \%)$ of the elderly chewed tobacco, $44(33.3 \%)$ of males were smokers and $38(28.7 \%)$ regularly consumed alcohol.

While in Khokhar A $(2001)^{10}$ study current smokers constituted $15.62 \%$ whereas $30.35 \%$ of the men were current consumers of alcohol. 12.5\% used tobacco and Singh Charan $(1995)^{11}$ reported that aged were addicted to one or more addictions. The addictions were significantly more $(\mathrm{p}<0.001)$ among males $(71.6 \%)$ than females $(29.3 \%)$. Tobacco smoking was the most common addiction.

\section{RECOMENDATIONS}

1. Ongoing activities of early diagnosis and treatment should be continued and strengthened.

2. Counseling is needed for de-addiction of elderly.

3. During my study period many eye cataract camps were conducted at RHTC, Paithan, with the collaboration of an NGO. So special drives to be launched to look into various aspects of elderly health with the help of NGO.

4. IEC activities about the needs of elderly and their solution should be launched including seminars; geriatric care Mela's, outreach programmes should be conducted.

\section{REFERENCS:}

1. Pathak J.D: Inquiry into 'Disorders of the Old ', Ind Jour of Community Med, pg.1-54, 1975.

2. Adegbehingbe BO, Fajemilehin BR, Ojofeitimi EO, Bisiriyu LA.Blindness and visual impairment among the elderly in Ife-Ijesha zone of Osun State, Nigeria: Community Ophthalmology 2006 Vol.54 (1); 59-62.

3. Singh MM, Murthy GV et al. A study of ocular morbidity among elderly population in a rural area of central India: Community Eye Care 1997 Vol. 45 (1); 61-65.

4. Sharma MK, Swami HM et al. An Epidemiological Study of Correlates of Osteo-Arthritis in Geriatric Population of UT Chandigarh: Indian Journal of Community Medicine Vol. 32, No. 1 (2007-01 - 2007-03).

5. Anil Jacob Purty, Joy Bazroy et al. Morbidity Pattern among the Elderly Population in the Rural Area of Tamil Nadu, India. Turk J Med Science 36(2006) 45-50.

6. Rahul Prakash, SK Choudhary, US Singh. A study of Morbidity pattern among geriatric population in an urban area of Udaipur Rajasthan. IJCM 2004:29 (1);pg 35-40.

7. Liu C, Androws GR. Prevalence and incidence of urinary incontinence in the elderly: A longitudinal study in South Australia. Chin Med journal (Engl), 2002 Jan;115(1):119-22.

8. Surekha Kishore, Ruchi Juyal et al. Morbidity Profile of Elderly Persons. JK Science; Department of Community Medicine, HIMS, Swami Rama Nagar, Dehradun (Uttaranchal); Vol. 9 (2), April-June 2007.pg 87-89.

9. Sonia Puri, Meenu Kalia et al: Profile of diabetes mellitus in elderly of Chandigarh, India: The Internet Journal of Endocrinology. 2007; Vol. 4(1).

10. Khokhar A, Mehra M. Life style and morbidity profile of geriatric Indian Journal of Medical Science 2001; 55(11), pg 609-15.

11. Singh Charan, Mathur JS et al. Social problems of aged in a rural population.Indian Journal of Community Medicine Vol. XX, no.1-4, Jan.-Dec., 1995. 